\title{
Ecology of oceanic coccolithophores. I. Nutritional preferences of the two stages in the life cycle of Coccolithus braarudii and Calcidiscus leptoporus
}

\author{
Aude Houdan, Ian Probert, Céline Zatylny, Benoît Véron*, Chantal Billard \\ Laboratoire de Biologie et Biotechnologies Marines, Université de Caen Basse-Normandie, Esplanade de la Paix, \\ 14032 Caen Cedex, France
}

\begin{abstract}
Coccolithus braarudii and Calcidiscus leptoporus are 2 coccolithophores (Prymnesiophyceae: Haptophyta) known to possess a complex heteromorphic life cycle, with alternation between a motile holococcolith-bearing haploid stage and a non-motile heterococcolith-bearing diploid stage. The ecological implications of this type of life cycle in coccolithophores are currently poorly known. The nutritional preferences of each stage of both species, and their growth response to conditions of turbulence were investigated by varying their growth conditions. Of the different culture media tested, only the synthetic seawater medium did not support the growth of both stages of $C$. braarudii and C. leptoporus. With natural seawater-based media, the growth rate of the haploid phase of both coccolithophores was stimulated by the addition of soil extract $\left(\mathrm{K} / 2: 0.23 \pm 0.02 \mathrm{~d}^{-1}\right.$ and $\mathrm{K} / 2$ with soil extract $0.35 \pm 0.01 \mathrm{~d}^{-1}$ for the $C$. braarudii haploid stage), while the diploid phase was not, indicating that the motile stage is capable of utilizing compounds present in soil extract or ingesting bacteria that are activated in enriched media. The addition of sodium acetate to the medium also stimulated the haploid phase of $C$. braarudii, and further experiments using labeled bacteria demonstrated the capacity for phagotrophy of this motile stage. The effect of nutrient concentrations on the growth rates of both species was evaluated, showing clear differences between the 2 phases of the life cycle, with higher growth rates for the diploid stage in nutrient-rich media $\left(\mathrm{K} / 2: 0.34 \pm 0.04 \mathrm{~d}^{-1}\right.$, $\mathrm{K} / 25: 0.29 \pm 0.01 \mathrm{~d}^{-1}, \mathrm{~K} / 100: 0.16 \pm 0.01 \mathrm{~d}^{-1}$ for the haploid stage of $C$. leptoporus). Responses of the 2 phases of both coccolithophores to physical turbulence were also different, with a haploid flagellate stage sensitive to mixing and a more resistant non-motile diploid stage. The results of these experiments strongly indicate that each morphological stage of $C$. braarudii and C. leptoporus corresponds to a different ecological niche, the motile haploid stage exploiting a more stable oligotrophic niche than the diploid non-motile stage, in accordance with field observations. The 2-dimensional phytoplankton niche space model of Margalef (1978; Oceanol Acta 1:493-509), defined by nutrients and turbulence, was amended to integrate this hypothesis.
\end{abstract}

KEY WORDS: Coccolithophore $\cdot$ Ecology $\cdot$ Life cycle $\cdot$ Nutrient $\cdot$ Turbulence $\cdot$ Heterotrophy

\section{INTRODUCTION}

Coccolithophores are considered 1 of the 3 main marine eukaryotic phytoplankton groups in terms of natural abundance, along with diatoms and dinoflagellates. These groups are responsible for the bulk of the export flux of organic matter to the ocean interior and sediments (see Falkowski et al. 2004 and references therein). They play a key role in the global cycles of carbon (production of calcified scales) and sulfur (production of dimethyl sulfide, see review by Malin \& Steinke 2004). Coccolithophores are present in all oceans, with the highest biodiversity in temperate and subtropical zones (Okada \& McIntyre 1979). These calcified haptophytes are generally associated with oceanic and oligotrophic waters, even if some species 
appear to be ubiquitous and some restricted to coastal zones. Certain coccolithophores are known to form extensive blooms in the ocean, such as Emiliania huxleyi, the most cosmopolitan species in present day oceans (see Paasche 2001 and references therein), and Coccolithus pelagicus (Tarran et al. 2001). The latter taxon was recently revised, and now is subdivided into Coccolithus pelagicus (Wallich) Schiller and Coccolithus braarudii (Gaarder) Baumann, Cachao, Young et Geisen (Sáez et al. 2003). Hereafter, Coccolithus pelagicus s.l. will be used in a collective sense when precise definition of the organism studied is difficult (the morphological variation between the 2 Coccolithus species is very low). Preliminary results on the biogeography of the 2 species composing C. pelagicus s.l. show that $C$. pelagicus s.s. has an arctic or subarctic distribution, while $C$. braarudii inhabits temperate waters and upwelling regimes (Geisen et al. 2002, Parente et al. 2004).

The discovery by Parke \& Adams (1960) some $40 \mathrm{yr}$ ago of a potential complex life cycle for Coccolithus was unexpected. Traditional coccolithophore taxonomy had been based on coccolith morphology; coccolithophores produce 2 very different types of calcified scales, i.e. heterococcoliths (formed of complex calcite crystal units of variable shape) and holococcoliths (formed of numerous minute euhedral crystallites) (for a review see Young et al. 2003). Parke \& Adams (1960) showed that the heterococcolithophore C. braarudii (as C. pelagicus in Parke \& Adams 1960) and the holococcolithophore Crystallolithus braarudii (as Cr. hyalinus) were, in fact, a single species linked in a heteromorphic life cycle. Using flow cytometric techniques, Houdan et al. (2004) recently confirmed this life cycle and established that these 2 distinct stages have different ploidy levels, the non-motile heterococcolithophore being diploid $(2 \mathrm{~N})$, while the motile holococcolithophore is haploid (N). This type of life cycle linking a heterococcolithophore with a holococcolithophore was also demonstrated for Calcidiscus leptoporus (Murray et Blackman) Loeblich et Tappan (Houdan et al. 2004), Coronosphaera mediterranea (Lohmann) Gaarder (Houdan et al. 2004), was confirmed for Emiliania huxleyi (Houdan et al. 2004) and was established for Calyptrosphaera sphaeroidea (Noel et al. 2004), and is probably widespread in oceanic coccolithophores (Billard \& Inouye 2004, Jordan et al. 2004). Although sometimes placed in different families, $C$. braarudii (Coccolithaceae) and C. leptoporus (Calcidiscaceae) are closely related morphologically and genetically (Edvardsen et al. 2000, Sáez et al. 2004), and both are temperate coccolithophores (Sáez et al. 2003). However, their ecology is still poorly understood, despite investigations into their distribution and ecological strategies through surveys such as those of
Price et al. (1998), Cachão \& Moita (2000), Renaud \& Klaas (2001), Beaufort \& Heussner (2001) and Renaud et al. (2002).

In our laboratory, clonal cultures of both phases of the life cycle of Coccolithus braarudii and Calcidiscus leptoporus (the heterococcolith phase associated with Crystallolithus rigidus), among other species, have been established (Houdan et al. 2004). We have conducted a series of experiments in order to compare the autecology of the different phases within the coccolithophore life cycle. Responses to a suite of environmental parameters have been studied, and this paper focuses on experiments designed to determine the relative nutritional preferences of each life-cycle phase, with a complementary study of the effect of turbulence.

\section{MATERIALS AND METHODS}

Strains and culture conditions. The original (nonaxenic) cultures of the species studied were obtained from the ALGOBANK-Caen culture collection at the University of Caen Basse-Normandie, France (Table 1). The cultures were clonal, 1 cell in the heterococcolith-bearing phase having been isolated from a mixed sample with a micropipette. Following phase change in culture, pure cultures of each phase (i.e. only 1 life-cycle phase present) were established by isolating 1 cell of each phase from the mixed-phase culture using the same method. The first phase change in cultures occurred for both species during the spring following their isolation, in May 1999 for Coccolithus braarudii and in April 2001 for Calcidiscus leptoporus. The stock cultures were maintained in sterile, singleuse polystyrene culture flasks (Iwaki), in filter-sterilized enriched seawater K/2 (without Tris buffer) medium (modified from Keller et al. 1987; Table 2) at $17^{\circ} \mathrm{C}$. Daylight fluorescent tubes provided an irradiance level of $25 \mu \mathrm{mol}$ photons $\mathrm{m}^{-2} \mathrm{~s}^{-1}$ measured with a $4 \pi$ quantum radiometer photometer (LiCor), with a photoperiod of 16:18 h light:dark. All experiments were performed under the temperature and light conditions described above and with triplicate cultures. The seawater used as the base for the medium was collected from surface waters of the English Channel, approximately $5 \mathrm{~km}$ from the Normandy coast, and aged for 2 or 3 mo before utilization, as generally recommended for the cultivation of microalgae.

The batch cultures were conducted in triplicate, and experiments were initiated following an acclimatization period of 4 transfers (duration approximately $3 \mathrm{wk})$, as recommended by Brand \& Guillard (1981), for each environmental condition tested. Growth was monitored daily (at the same hour of the day) by man- 
ual counting using a Malassez counting slide and/or fluorometric measurement of in vivo chlorophyll $a$ (Turner Designs 700) for about $10 \mathrm{~d}$ (until the end of the stationary phase). Correlations (linear regressions) between cell counts and fluorescence were calculated for each species (coefficient of regression $>0.8$ ). Specific growth rates were calculated following the equation $k=\ln \left(C / C_{0}\right) / t$, where $t$ is the duration of experiments, $C$ is the fluorescence reading at time $t$ and $C_{0}$ is the initial fluorescence reading. The growth rates used in this work were measured before the end of the exponential phase for each culture, on Day 5 of the experiment.
Nutrient concentration experiments and experimental media. To study the effect of nutrient availability on growth, the selected algae were cultured in different dilutions of $\mathrm{K}$ medium: $\mathrm{K} / 2, \mathrm{~K} / 5, \mathrm{~K} / 10, \mathrm{~K} / 25$ and $\mathrm{K} / 100$. Only phosphorus and nitrogen nutrients in the medium were submitted to dilution; other constituents were maintained at the concentration of $\mathrm{K} / 2$. These experiments were undertaken, respectively, 3 and $2 \mathrm{yr}$ after the phase change of Coccolithus braarudi and Calcidiscus leptoporus.

Different culture media were tested (Table 2) on the 2 species studied. Two media were based on natural seawater, i.e. $\mathrm{K} / 2$ and $\mathrm{K} / 2$ with soil extract (K/2SE).

Table 1. Origin of the experimental species (ALGOBANK culture collection; available at www.unicaen.fr/algobank)

\begin{tabular}{|lcccc|}
\hline Strain & Species (heterococcolithophore stage) & Origin & Date of isolation & Date of phase change \\
\hline AC 392 & Coccolithus braarudii & Arcachon, Atlantic coast of France & Feb 1999 & May 1999 \\
AC 370 & Calcidiscus leptoporus & Off South Africa, South Atlantic & Sep 2000 & Apr 2001 \\
\hline
\end{tabular}

Table 2. Nutrient regimes of the 3 media tested $(\mu \mathrm{M})$. Media $\mathrm{K} / 2$ and $\mathrm{K} / 2$ with soil extract (K/2SE) are based on natural seawater (see 'Materials and methods')

\begin{tabular}{|c|c|c|c|c|c|c|c|}
\hline & $\mathrm{K} / 2$ & $\mathrm{~K} / 2 \mathrm{SE}$ & ESAW & $\mathrm{K} / 5$ & $\mathrm{~K} / 10$ & $\mathrm{~K} / 25$ & $\mathrm{~K} / 100$ \\
\hline \multicolumn{8}{|c|}{ Salt solution I-anhydrous salts } \\
\hline $\mathrm{NaCl}$ & & & $363 \times 10^{3}$ & & & & \\
\hline $\mathrm{Na}_{2} \mathrm{SO}_{4}$ & & & $25 \times 10^{3}$ & & & & \\
\hline $\mathrm{KCl}$ & & & $8.04 \times 10^{3}$ & & & & \\
\hline $\mathrm{NaHCO}_{3}$ & & & $2.07 \times 10^{3}$ & & & & \\
\hline $\mathrm{KBr}$ & & & 725 & & & & \\
\hline $\mathrm{H}_{3} \mathrm{BO}_{3}$ & & & 372 & & & & \\
\hline $\mathrm{NaF}$ & & & 65.70 & & & & \\
\hline \multicolumn{8}{|c|}{ Salt solution II-hydrated salts } \\
\hline $\mathrm{MgCl}_{2} 6 \mathrm{H}_{2} \mathrm{O}$ & & & $41.20 \times 10^{3}$ & & & & \\
\hline $\mathrm{CaCl}_{2} 2 \mathrm{H}_{2} \mathrm{O}$ & & & 9.14 & & & & \\
\hline $\mathrm{SrCl}_{2} 6 \mathrm{H}_{2} \mathrm{O}$ & & & 82 & & & & \\
\hline \multicolumn{8}{|c|}{ Major nutrients } \\
\hline $\mathrm{NaNO}_{3}$ & 500 & 500 & 500 & 200 & 100 & 40 & 5 \\
\hline $\mathrm{NH}_{4} \mathrm{Cl}$ & 5 & 5 & 5 & 1 & 0.5 & 0.2 & 0.1 \\
\hline $\mathrm{KH}_{2} \mathrm{PO}_{4}$ & 25 & 25 & 25 & 10 & 5 & 1 & 0.5 \\
\hline \multicolumn{8}{|l|}{ Metals } \\
\hline $\mathrm{CuSO}_{4}$ & 0.005 & 0.005 & 0.005 & 0.005 & 0.005 & 0.005 & 0.005 \\
\hline $\mathrm{ZnSO}_{4}$ & 0.05 & 0.05 & 0.05 & 0.05 & 0.05 & 0.05 & 0.05 \\
\hline $\mathrm{Na}_{2} \mathrm{MoO}_{4}$ & 0.005 & 0.005 & 0.005 & 0.005 & 0.005 & 0.005 & 0.005 \\
\hline $\mathrm{CoCl}_{2}$ & 0.005 & 0.005 & 0.005 & 0.005 & 0.005 & 0.005 & 0.005 \\
\hline $\mathrm{H}_{2} \mathrm{SeO}_{3}$ & 0.005 & 0.005 & 0.005 & 0.005 & 0.005 & 0.005 & 0.005 \\
\hline \multicolumn{8}{|l|}{ EDTA } \\
\hline $\mathrm{Na}_{2}$ EDTA & 50 & 50 & 50 & 50 & 50 & 50 & 50 \\
\hline NaFeEDTA & 5 & 5 & 5 & 5 & 5 & 5 & 5 \\
\hline \multicolumn{8}{|l|}{ Vitamins } \\
\hline Vitamin B12 & 0.005 & 0.005 & 0.005 & 0.005 & 0.005 & 0.005 & 0.005 \\
\hline Biotin & 0.0005 & 0.0005 & 0.0005 & 0.0005 & 0.0005 & 0.0005 & 0.0005 \\
\hline Thiamine & 0.05 & 0.05 & 0.05 & 0.05 & 0.05 & 0.05 & 0.05 \\
\hline Soil extract & & $1.5 \mathrm{ml}$ in 30 & & & & & \\
\hline
\end{tabular}


Garden soil (collected in Caen, France; free from fertilizer and pesticide additions) was autoclaved in seawater (1 kg in $2 \mathrm{l}$ ) for $30 \mathrm{~min}$ at $120^{\circ} \mathrm{C}$ and then filtered through Whatman No. 1 filter paper. The filtrate was autoclaved again for $30 \mathrm{~min}$ at $120^{\circ} \mathrm{C}$, and finally $50 \mathrm{ml}$ of this solution was added to $950 \mathrm{ml}$ of medium (following the proportions used by Cosson 1987). The third medium was completely synthetic, the modified ESAW medium (Berges et al. 2001), enriched following the $K$ medium protocol for nutrients (Table 2). The 2 stages of both coccolithophores were cultured in the 3 media.

Heterotrophy. In order to test the potential heterotrophy of Coccolithus braarudii, both stages of this species were cultured in K/5 medium enriched with sodium acetate $\left(100 \mu \mathrm{mol} \mathrm{l}^{-1}\right.$, the concentration used for Isochrysis sp. in Liu \& Lin 2001). As controls, the non-motile and motile stages were grown in K/5 without acetate.

In a second experiment, the 2 stages of Coccolithus braarudii were grown in 2 different solutions based on the remaining liquids from a stationary-phase, nonaxenic culture of this species (and containing originally a mixture of both stages of the life cycle). One solution resulted from the filtration (through $0.22 \mu \mathrm{m}$ pore size cellulose acetate membrane filters, Whatman) of half of the stationary-phase culture, while the other solution was prepared by centrifugation (3000 rpm [500 $\times g$ ] for 15 min to eliminate algal cells and debris) of the other half of the culture. Both solutions (filtered and centrifuged) were enriched with sterile K/5 medium supplements. Each stage of C. braarudii was cultured separately in these enriched solutions.

In parallel, another experiment was conducted on Coccolithus braarudii to test for potential phagotrophy. The motile haploid phase (only this stage has a haptonema, a feature which permits phagotrophy in prym-

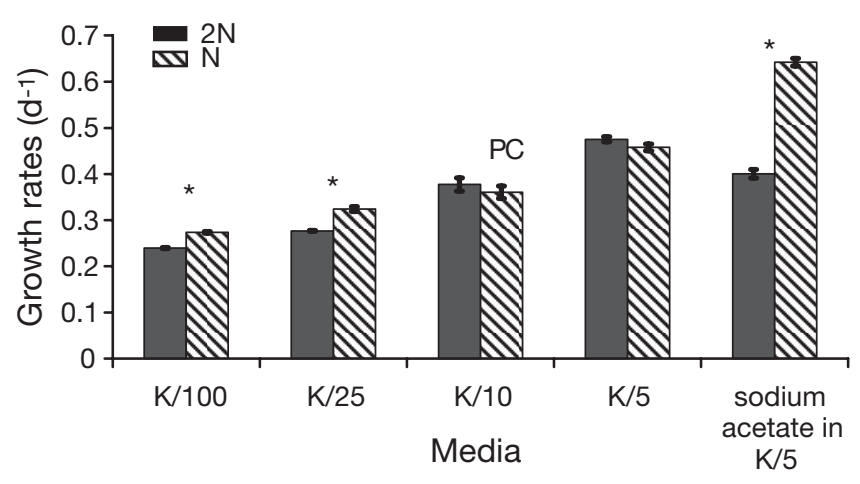

Fig. 1. Coccolithus braarudii. Growth rates of the 2 stages (2N: diploid stage; $\mathrm{N}$ : haploid stage) in 4 concentrations of $\mathrm{K}$ medium and in the presence of sodium acetate in $\mathrm{K} / 5$ $\left(100 \mu \mathrm{mol} \mathrm{l} \mathrm{l}^{-1}\right)$ (mean $\left.\pm \mathrm{SE}_{;} \mathrm{n}=3\right)$. PC: phase change in the culture ${ }_{i}^{*}$ : significantly different growth rates between the 2 stages (Mann-Whitney test, $\mathrm{p}<0.05$ ) nesiophytes) was cultivated on a medium with added labeled bacteria. The bacterial strain, originating from an old culture of the haploid stage of $C$. braarudii, was isolated on agar plates and grown in saline peptone water (1.5\% peptone, $1.5 \% \mathrm{NaCl}, \mathrm{w} / \mathrm{v}, \mathrm{pH} 7.2)$. Bacteria were harvested, washed $\left(2000 \times g\right.$ at $4^{\circ} \mathrm{C}$ for $15 \mathrm{~min})$, resuspended in phosphate-buffered saline $(\mathrm{pH} 7.4)$ and the optical density $\left(\mathrm{OD}_{540}\right)$ adjusted to 1.5-2.0. The bacteria were then labeled by incubation with $0.1 \mathrm{mg}$ FITC (Isomer I, Sigma) $\mathrm{ml}^{-1}, 0.1 \mathrm{M}$ $\mathrm{NaHCO}_{3}, \mathrm{pH} 9.5$, at $4{ }^{\circ} \mathrm{C}$ in the dark for $1 \mathrm{~h}$. Bacteria were pelleted at $1500 \times g$ for 5 min and washed free of unbound FITC with phosphate-buffered saline (5 to 10 times). After washing, the bacterial concentration was determined in a counting chamber and adjusted to $10^{8}-10^{9}$ cells $\mathrm{ml}^{-1}$ (protocol modified from LópezDóriga et al. 2000). A culture of the motile haploid phase of $C$. braarudii was incubated with $2 \mathrm{ml}$ of labeled bacteria and stored at $17^{\circ} \mathrm{C}$ in the dark. Algal cells were then observed with a fluorescent light microscope (Zeiss standard LAB 16) every hour for $5 \mathrm{~h}$ and after a period of $24 \mathrm{~h}$.

Turbulence. In order to test the potential effect of physical disturbance on Coccolithus braarudii and Calcidiscus leptoporus, triplicate cultures of each phase of the life cycle were grown in K/2 medium and placed on a roller table $(1 \mathrm{rpm})$ for $10 \mathrm{~d}$, and growth rates were measured after $3 \mathrm{~d}$ of culturing. When cultures rapidly died under these conditions, a repeat control experiment was conducted after $1 \mathrm{wk}$ to confirm the result. Controls were cultured in similar conditions without turbulence.

Statistical analyses. Statistical analyses were conducted with Statgraphs software, using the MannWhitney test with $\mathrm{p}=0.05$.

\section{RESULTS}

\section{Nutrient concentration experiments and experimental media}

The growth rates of the 2 phases of Coccolithus braarudii decreased in relation to decreasing concentrations of nutrients in K medium (Fig. 1). Four nutrient concentrations were tested on this species $(K / 5, K / 10$, $\mathrm{K} / 25, \mathrm{~K} / 100$ ). The growth rate of the diploid heterococcolith-bearing phase decreased more rapidly in media with less nitrogen and phosphorus (respectively, a decrease of 21,42 and $50 \%$ for the diploid stage cultivated in $\mathrm{K} / 10, \mathrm{~K} / 25$ and $\mathrm{K} / 100$ compared to cultures in $\left.\mathrm{K} / 5: 0.47 \pm 0.01 \mathrm{~d}^{-1}\right)$ than the growth rate of the motile haploid phase (decrease of 20, 28 and $39 \%$, growth rates in $\mathrm{K} / 5$ : $\left.0.46 \pm 0.01 \mathrm{~d}^{-1}\right)$. Statistically significant differences were then observed between both stages 
Table 3. Coccolithus braarudii, Calcidiscus leptoporus. Growth rates $( \pm \mathrm{SE})$ of the 2 stages in $\mathrm{K} / 2$ medium and in $\mathrm{K} / 2$ with soil extract (K/2SE)

\begin{tabular}{|lcccc|}
\hline & \multicolumn{2}{c}{ Haploid stage } & \multicolumn{2}{c|}{ Diploid stage } \\
& $\mathrm{K} / 2$ & $\mathrm{~K} / 2 \mathrm{SE}$ & $\mathrm{K} / 2$ & $\mathrm{~K} / 2 \mathrm{SE}$ \\
\hline C. braarudi & $0.229 \pm 0.024$ & $0.346 \pm 0.005$ & $0.537 \pm 0.014$ & $0.536 \pm 0.005$ \\
C. leptoporus & $0.085 \pm 0.004$ & $0.235 \pm 0.013$ & $0.260 \pm 0.009$ & $0.230 \pm 0.017$ \\
\hline
\end{tabular}

2 other media $\left(\mathrm{K} / 25: 0.29 \pm 0.01 \mathrm{~d}^{-1}\right.$, $15 \%$ decrease compared to growth rates obtained in $\mathrm{K} / 2$; $\mathrm{K} / 100: 0.16 \pm$ $\left.0.01 \mathrm{~d}^{-1}, 54 \%\right)$. Growth rates of the non-motile diploid phase were similar (statistically not significant) in the 3 richer media (around $0.40 \mathrm{~d}^{-1}$ ) and decreased only in K/100 (0.29 \pm 0.01 $\mathrm{d}^{-1}, 35 \%$ decrease), the medium most deficient in nitrogen and phosphorus.

in K/25 and K/100 (Mann-Whitney test, p < 0.05; Fig. 1). Moreover, a phase change was observed from the flagellate haploid phase to the non-motile diploid phase in the K/10 medium in this experiment (Fig. 1). Phase changes were not synchronized, and affected only a small proportion of the cultures. Estimating the number of resulting diploid cells was difficult because of their own subsequent divisions in the cultures. These phase changes were very rare in more nutrientdeficient media.

Concerning the experimental media tested, the growth rates of the diploid phase were significantly superior (Mann-Whitney test, $p<0.05$ ) to those of the haploid phase in K/2 and in K/2SE (Table 3). However, the presence of soil extract did not affect the growth of the diploid stage, whereas the haploid stage was stimulated (30\% higher growth rate) in comparison to the growth rate in K/2 medium. Neither phase grew in the artificial medium ESAW; the haploid phase died after the first transfer, while the diploid phase survived until the last transfer of the acclimatization period.

For Calcidiscus leptoporus, a significant correlation was obtained between growth rates of the flagellate haploid phase and nutrient concentrations (Fig. 2), with similar rates in $\mathrm{K} / 2$ and $\mathrm{K} / 10$ (respectively, $0.34 \pm$ 0.04 and $0.36 \pm 0.04 \mathrm{~d}^{-1}$ ) and slower growth rates in the

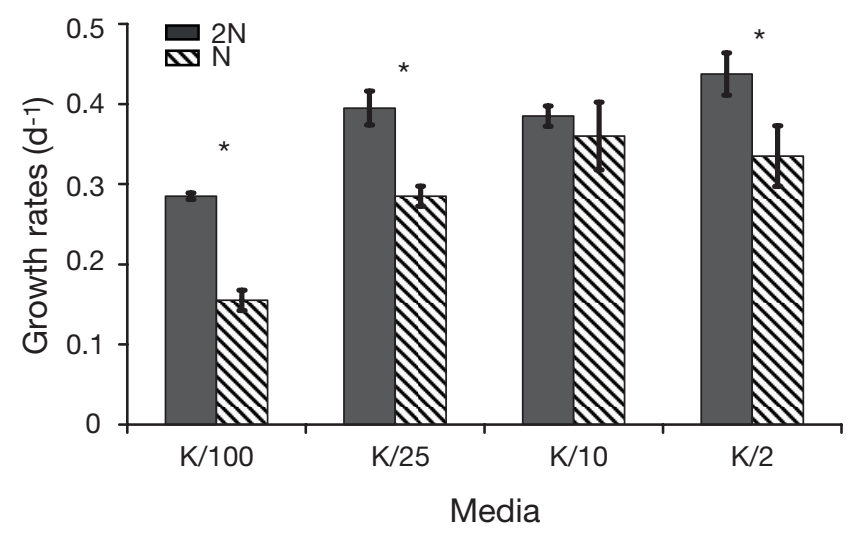

Fig. 2. Calcidiscus leptoporus. Growth rates of the 2 stages ( $2 \mathrm{~N}$ : diploid stage; $\mathrm{N}$ : haploid stage) in 4 concentrations of $\mathrm{K}$ medium (mean $\pm \mathrm{SE}_{;} \mathrm{n}=3$ ). * Significantly different growth rates between the 2 stages (Mann-Whitney test, $\mathrm{p}<0.05$ )
The diploid phase grew faster than the haploid phase in all media tested, except K/10, in which growth rates were similar. An interesting phenomenon was observed for the haploid stage, with appearance in the experimental cultures of pseudo-colonies (Fig. 3), composed of 4 to $>16$ flagellate cells delimited by a loose envelope without coccoliths. The simultaneous appearance of these pseudo-colonies in each of our triplicate cultures precludes a culture artifact. The presence of these pseudo-colonies was correlated with the nutrient concentration in the medium (Fig. 4), with $80 \%$ colonies in $\mathrm{K} / 2,60 \%$ in $\mathrm{K} / 25$ and none in $\mathrm{K} / 100$ (the most nutrient-deficient medium). The absence of coc-

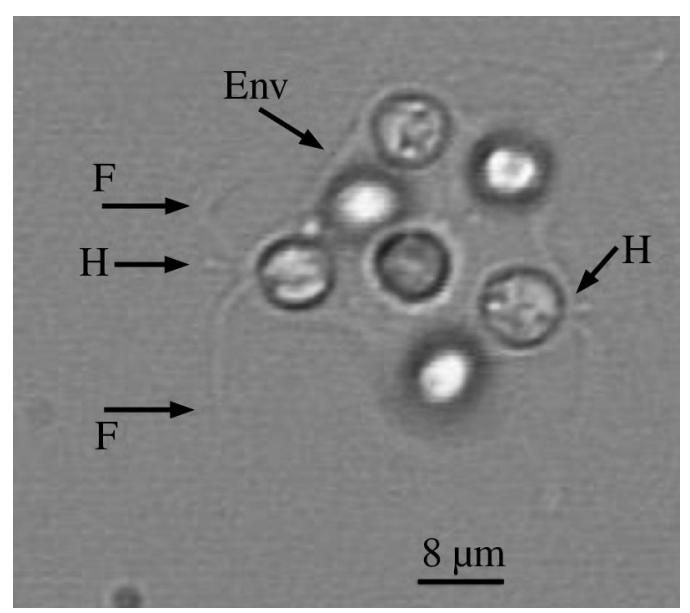

Fig. 3. Calcidiscus leptoporus. Pseudo-colony-forming flagellates (haploid stage) in K/2 medium. Env: envelope; F: flagellum; $\mathrm{H}$ : haptonema

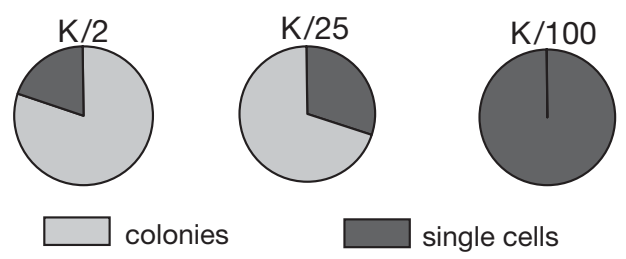

Fig. 4. Calcidiscus leptoporus. Proportions of motile cells and pseudo-colonies (haploid stage) in 3 concentrations of $\mathrm{K}$ medium $(K / 2, K / 25$ and $K / 100)$ 
coliths was noticed in many cultures in richer medium $(\mathrm{K} / 2)$. The pseudo-colonies did not give rise to normal cells and died after 10 to $15 \mathrm{~d}$, like normal cells.

The growth rate of the diploid phase of Calcidiscus leptoporus was higher in K/2 than in K/2SE (Table 3). The situation was reversed for the haploid stage, which grew well in the presence of soil extract. In K/2SE, both phases had similar growth rates. There was no growth in either stage of this species in the artificial medium (ESAW). As for Coccolithus braarudi, the diploid stage survived longer than the haploid stage before their death.

\section{Heterotrophy}

The 2 stages of Coccolithus braarudii presented different growth rates in the K/5 medium enriched with sodium acetate. The diploid stage was inhibited (15\% inhibition) with respect to the control, while the haploid stage showed an increased growth rate $40 \%$ stimulation) in the presence of sodium acetate, at a concentration of $100 \mu \mathrm{mol} \mathrm{l}^{-1}$ (Fig. 1).

Growth of Coccolithus braarudi in the 2 media based on the remaining liquid from a stationary-phase culture of the same strain gave indications about its potential mixotrophy. Growth rates of both phases were significantly higher (Mann-Whitney test, p < 0.05 ) in the medium prepared by centrifugation than in the medium resulting from $0.22 \mu \mathrm{m}$ filtration (Fig. 5). Inhibition of the growth rates of the haploid and diploid phases was, respectively, 33 and $25 \%$ in the filtered (i.e. sterilized) medium $(0.09 \pm 0.01$ and $0.23 \pm$ $\left.0.01 \mathrm{~d}^{-1}\right)$ compared with the centrifuged medium $\left(0.14 \pm 0.02\right.$ and $\left.0.31 \pm 0.01 \mathrm{~d}^{-1}\right)$.

The experiment in which bacteria labeled with FITC were added to the culture medium was designed to

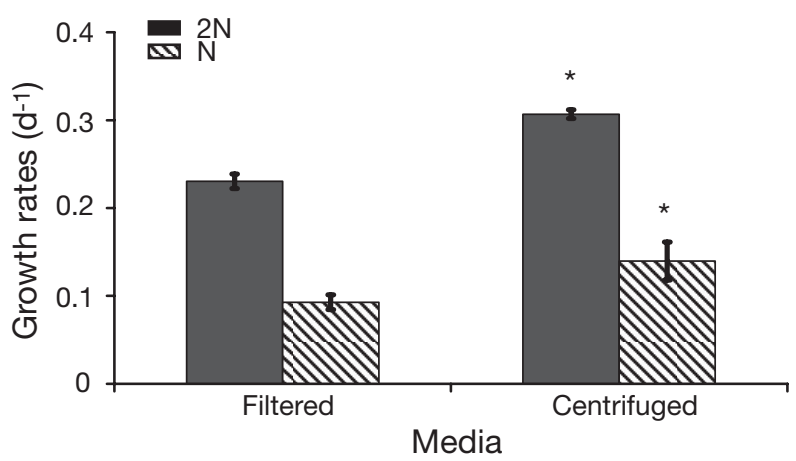

Fig. 5. Coccolithus braarudii. Growth rates of the 2 stages (2N: diploid stage; N: haploid stage) in media based on filtered or centrifuged solutions from a culture in the stationary growth phase (see 'Materials and methods') (mean $\pm \mathrm{SE}_{;} \mathrm{n}=3$ ). *Significantly different growth rates between filtered and centrifuged media (Mann-Whitney test, $\mathrm{p}<0.05$ )

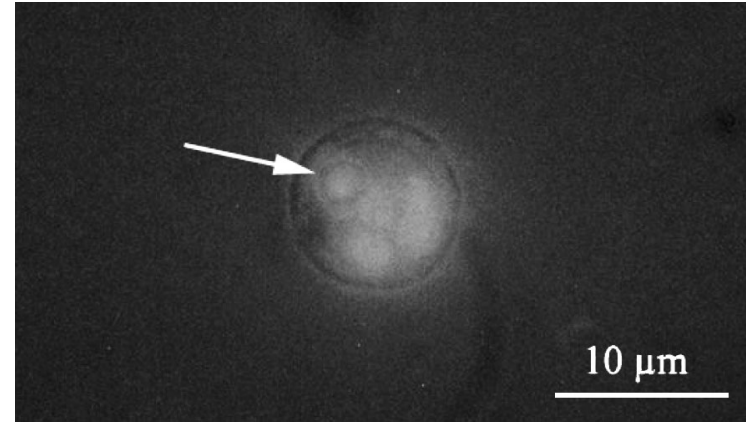

Fig. 6. Coccolithus braarudii. Haploid cell showing a green fluorescent vacuole (arrow) following incubation with FITClabeled bacteria

evaluate the potential phagotrophy of the haploid stage of Coccolithus braarudii. Observations showed the presence of vacuoles with green fluorescence located next to the basal pole (posterior part) of the flagellate cells after 2 to $3 \mathrm{~h}$ of incubation in the dark with labeled bacteria (Fig. 6, arrow). Frequent observations during the following hours and $24 \mathrm{~h}$ after incubation demonstrated that the number of cells containing green fluorescent vacuoles increased with incubation time.

\section{Turbulence}

The response of the 2 phases of Coccolithus braarudii was clearly different in the conditions of physical disturbance. Compared to the control $\left(0.68 \pm 0.04 \mathrm{~d}^{-1}\right)$, growth of the non-motile diploid phase was slightly inhibited $\left(0.58 \pm 0.01 \mathrm{~d}^{-1} ; 14 \%\right.$ inhibition $)$, whereas the haploid flagellate phase did not grow and fluorescence declined to zero very quickly (about $3 \mathrm{~d}$ ) in cultures (Fig. 7). Moreover, a phase change was observed in the haploid culture (Fig. 8a), with a progressive shift towards non-motile cells a few hours following the onset of turbulent conditions (Fig. 8b-f). The images of this phase change in turbulent conditions were published previously in Houdan et al. (2004). Fusion of the 2 cells had already commenced when the pair was first observed (Fig. 8b). The fusing cells were of similar size, and 1 pair of cells retained the flagella during the fusion process. The complete fusion of the 2 cells was completed within a few minutes, the resultant nonmotile zygote retaining a complete cover of holococcoliths formed by the fusion of the coccospheres of the gametes (Fig. 8d). The cell died within approximately 30 min on the microscope slide, by which time a single heterococcolith had been formed within the cell (Fig. 8e, arrow). Fig. 8f illustrates a heterococcolithbearing cell with the coccosphere still in formation 
(picture taken $24 \mathrm{~h}$ after the beginning of turbulent conditions) by the fusion of 2 holococcolith-bearing cells (a coccolith was in formation inside the cell, arrow). Results were similar for Calcidiscus leptoporus (Fig. 9); there was an absence of growth of the haploid flagellate phase in turbulent conditions and partial inhibition of the non-motile diploid stage, with $56 \%$ inhibition compared to the control $\left(0.49 \pm 0.01 \mathrm{~d}^{-1}\right)$. Phase changes were not observed for this species.

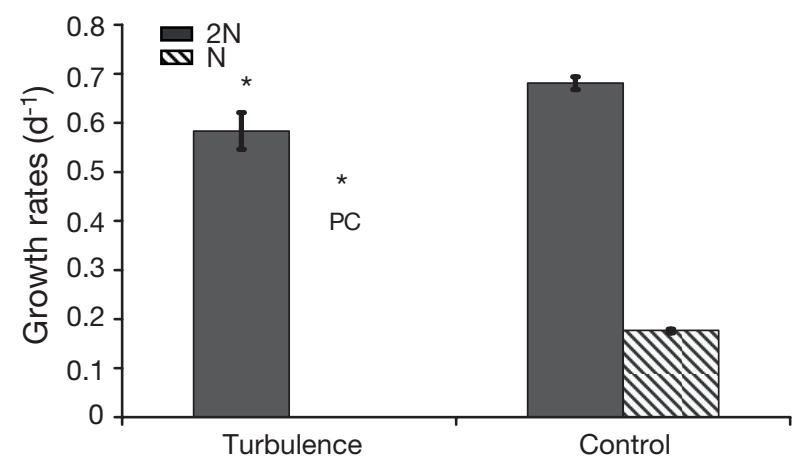

Fig. 7. Coccolithus braarudii. Influence of turbulence on the growth rate of the 2 stages ( $2 \mathrm{~N}$ : diploid stage; $\mathrm{N}$ : haploid stage) cultivated in $\mathrm{K} / 2$ medium (mean $\pm \mathrm{SE} ; \mathrm{n}=3$ ). $\mathrm{PC}$ : phase change; ${ }^{*}$ Growth rates significantly different from the control (MannWhitney test, $\mathrm{p}<0.05$ )

\section{DISCUSSION}

Different aspects of the nutrition of 2 oceanic temperate coccolithophores were investigated in this study. Three culture media were tested here; only the synthetic medium (ESAW) did not support growth of both stages in the life cycle of Coccolithus braarudii and Calcidiscus leptoporus. Oceanic coccolithophores are difficult to cultivate in artificial seawater media,

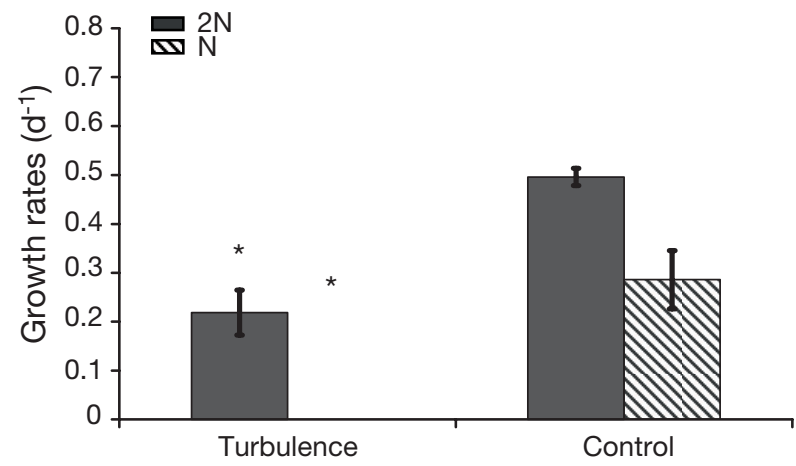

Fig. 9. Calcidiscus leptoporus. Influence of turbulence on the growth rate of the 2 stages $(2 \mathrm{~N}$ : diploid stage; $\mathrm{N}$ : haploid stage) cultivated in $\mathrm{K} / 2$ medium (mean $\pm \mathrm{SE} ; \mathrm{n}=3$ ). *Growth rates significantly different from the control (Mann-Whitney test, $\mathrm{p}<0.05)$

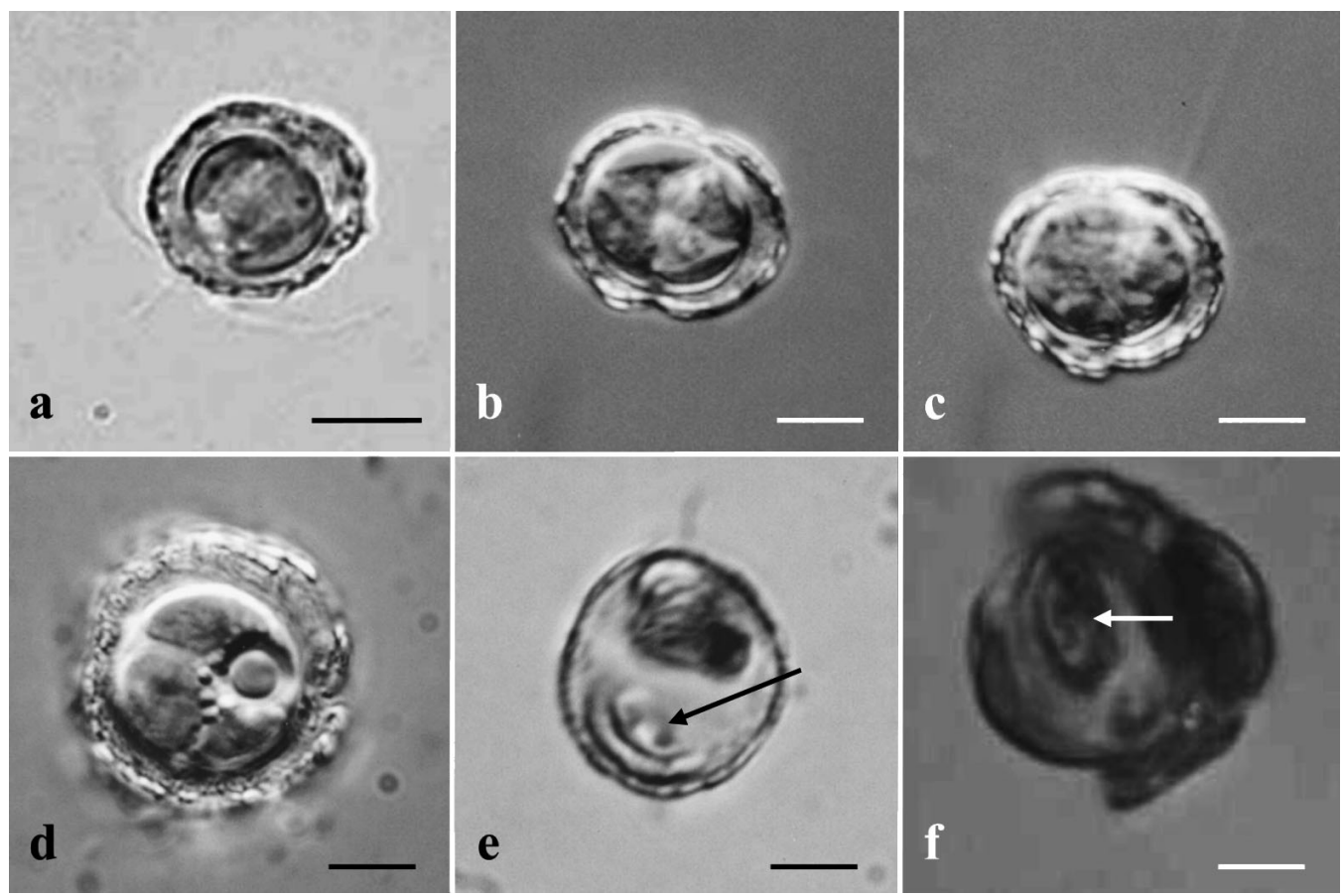

Fig. 8. Coccolithus braarudii. Observations of phase change (haploid vs. diploid): (a) holococcolith-bearing cell or motile haploid stage; (b-e) sequential images of fusion of 2 holococcolith-bearing cells with formation of the first heterococcolith (e, arrow) within the fused cell; (f) a heterococcolith-bearing cell with a heterococcolith in formation inside the cell (arrow). (a) to (e) modified from Houdan et al. (2004). Scale bars $=2 \mathrm{~mm}$ 
and, from our experience in the laboratory, only members of the Pleurochrysidaceae and Hymenomonadaceae, as well as some members of the Noelhaerhabdaceae (Emiliania huxleyi), are capable of developing in this kind of medium (Probert \& Houdan 2004). E. huxleyi was tested by Berges et al. (2001) in artificial seawater medium, and, according to the authors, this species grew better in the medium based on artificial seawater than in media based on natural seawater. E. huxleyi is the only species known to present this type of response among the coccolithophores studied so far. In our experiments, however, the nonmotile diploid heterococcolith-bearing stage of Coccolithus braarudii died only at the end of the acclimatization period recommended by Brand \& Guillard (1981), while the haploid holococcolith-bearing flagellate stage died a few days after inoculation into the artificial medium. The same pattern was observed for $C$. leptoporus, and it could be hypothesized that the heterococcolith-bearing stages of both species are less demanding regarding the composition of the culture medium. These results confirmed the observations of Noel et al. (2004), who determined that the heterococcolith-bearing cells of Calyptrosphaera sphaeroidea appear to tolerate a wider range of nutrient compositions compared with holococcolith-bearing cells. Nevertheless, another explanation could be that the nonmotile diploid cells are larger (about $20 \mu \mathrm{m}$ in diameter) than the haploid flagellates (approximately 10 to $12 \mu \mathrm{m}$ ) and, therefore, that the diploid stage could have more abundant reserve compounds and may make use of them in nutrient-depleted conditions. Malone (1980) stressed that many phytoplankton species possess a large vacuole within which nutrient reserves can be accumulated and that the volume of this vacuole increases with the cell volume. With the 2 other seawater-based media tested, the haploid stage of both species was stimulated by the presence of soil extract, while the diploid stage was not affected. Addition of soil extract in a medium is known to provide various trace elements and vitamins essential for algal growth (see Berges et al. 2001), metal complexing organic compounds that sequester potentially toxic metals, and organic compounds that keep iron in solution and allow for its photoreduction. The stimulation by soil extract of the haploid stage may indicate that the motile haploid stage is capable of utilizing the compounds present in soil extract, or capable of ingesting the bacteria that are stimulated in this type of enriched medium. The haploid stage could thus be mixotrophic (osmotrophic and/or phagotrophic), whereas the diploid stage would have no (or less) mixotrophic capacity. The results of our experiments conducted with sodium acetate added to the medium and with media based on liquid recovered from a culture in the stationary-growth phase by centrifugation or filtering through a filter with a pore size of $0.22 \mu \mathrm{m}$ provide evidence to support this hypothesis. In the presence of sodium acetate, the haploid stage of $C$. braarudii behaved as in the medium containing soil extract, with stimulation of the haploid stage (utilization of sodium acetate or ingestion of bacteria, growth rates $30 \%$ higher), corroborating the idea of its potential mixotrophy. The growth rate of the diploid stage was inhibited in the presence of sodium acetate $15 \%$ inhibition); this phenomenon could be linked to the development of bacteria, which compete with the coccolithophore for nutrients. Concerning the media based on liquid recovered from an old culture of $C$. braarudii (containing a mixture of the 2 stages), the filtered medium contained few or no bacteria, while bacteria were present in high numbers in the centrifuged medium (a common feature in aging cultures). In this case, both stages were stimulated in the centrifuged medium, the haploid phase more so than the diploid phase.

These results could be explained in part by phagotrophy, a well known capacity for certain noncalcifying prymnesiophytes (Jones et al. 1994, Tillmann 1998). Such a capacity was detected very early in coccolithophores, when Parke \& Adams (1960) noted the ability of the motile stage of Coccolithus to ingest carbon particles. Klaveness (1973) demonstrated the same aptitude for the holococcolithophore Calyptrosphaera sphaeroidea. Only the haploid flagellate stage of $C$. braarudii was studied in the experiments with labeled bacteria, since motile cells (with an emergent haptonema) seem to be a prerequisite for phagotrophy in haptophytes (Kawachi et al. 1991, Jones et al. 1994, Tillmann 1998). We showed that this stage was capable of phagotrophy, with the presence of fluorescent food vacuoles in cells cultivated with FITC-labeled bacteria (Fig. 6). The fact that such vacuoles were observed at the posterior end of the coccolithophore cell indicates a predation behavior similar to that of non-calcified prymnesiophytes such as Chrysochromulina (Kawachi et al. 1991) or Prymnesium (Tillmann 1998).

To complement this aspect of nutrition in coccolithophores, the effect of nutrient concentrations on growth rates of Coccolithus braarudii and Calcidiscus leptoporus was evaluated. The diploid phase of $C$. braarudii seems to be more competitive in nutrientrich media than the haploid phase, which could dominate under conditions of nutrient scarcity. Observations of routine cultures confirm that in $\mathrm{K} / 2$ medium the diploid phase has a significantly higher growth rate than the haploid phase (Mann-Whitney test, $\mathrm{p}<0.05$ ). Furthermore, phase changes were noted in cultures grown in K/2 and K/10 (considered a more favorable 
media), but they were very rarely observed in lower nutrient regimes such as K/25 or K/100 (in this case, diploid cells were observed only for a few days and died very rapidly). These results agree with those of Richerd et al. (1993), who demonstrated that haploid macroalgae are more competitive than their diploid counterparts in nutrient-depleted media.

Different hypotheses have been suggested to explain the persistence of haplo-diplontic life cycles in nature. Studies of seasonal distributions of temperate phytoplankton show that diatoms, the first group to develop in early spring following a mixing event, are 'r-selected' strategists and diploid organisms, whereas dinoflagellates, which appear later, are 'K-selected' and haploids. According to Lewis (1985), natural selection in phytoplankton could optimize the utilization and storage of nitrogen and phosphorus, and render an advantage to haploid organisms with lower requirements for these elements in oligotrophic conditions.

Lewis' hypothesis can be applied to coccolithophores such as Coccolithus braarudii, and, in light of the results presented here, we can argue that its flagellate haploid stage (with a significantly higher growth rate in nutrient-deficient media and a potential for phagotrophy/mixotrophy compared to the diploid stage) is adapted to an oligotrophic ecological niche. The observations of Kleijne (1993), showing that holococcolithophores (many of which are in fact haploid stages of heterococcolithophores; Billard 1994, Billard \& Inouye 2004, Houdan et al. 2004) are primarily found in oligotrophic waters, are consistent with this hypothesis. In contrast, the diploid stage appears to be more competitive in terms of nutrients than the haploid stage, and could be considered to be more adapted to a nutrient-rich ecological niche. These hypotheses are concordant with the results obtained by Noel et al. (2004) on Calyptrophora sphaeraoidea and with their interpretation of a diploid stage that tolerates a wider range of nutrient compositions. This is also in agreement with Valéro et al. (1992), who argue that, in ecological terms, a haplo-diploid life cycle is generally considered to be an adaptation to an environment that is seasonally variable or that contains 2 different niches. Our results relating to the behavior of the 2 stages of $C$. braarudii in conditions of turbulence also agree with this view, with a haploid phase that is sensitive to mixing and a diploid stage that is more resistant. Furthermore, physical disturbance can rapidly induce phase changes in this species.

Calcidiscus leptoporus exhibits some clear differences between its 2 phases in terms of growth rates with respect to the nutrient concentrations tested. The diploid stage always had significantly (Mann-Whitney test, $\mathrm{p}<0.05$ ) higher growth rates than the haploid stage. Both phases showed a correlation between nutrient concentrations and growth rates, higher rates being obtained with higher nutrient regimes. However, aberrant pseudo-colonies of flagellate haploid cells appeared in certain cultures, in association with the richness of the medium (Fig. 4). The production of such pseudo-colonies of individual cells swimming in different directions inside a loose envelope implies a high metabolic cost, and this phenomenon, when observed in culture, may reflect a poor adaptation of this stage to higher nutrient concentrations. Indeed, such pseudo-colonies of $C$. leptoporus have never been encountered in nature, in contrast to the singlecelled flagellate haploid stage, which is very common in oligotrophic or stratified waters (Kleijne 1993, Cros 2002). We therefore assume that C. leptoporus has an ecological niche similar to that of Coccolithus braarudii, the haploid stage being adapted to more nutrient-depleted waters than the diploid stage. Oligotrophic waters are generally stratified (low-nutrient concentrations are consequences of stratification), and, in such environments, the motile stages of both of these oceanic coccolithophores could be an advantage, especially since our results regarding the turbulence effect show that such haploid stages are inhibited by mixing conditions. Young (1994) pointed out earlier that the presence of flagellates in certain coccolithophores (his 'placolith-bearing group') could enhance the ability of these species to exploit stratified, nutrient-poor environments. The motile capacity of the haploid stage could also limit cell sinking and therefore maintain this stage in the photic zone, while the dense, plated diploid stage could sink through the water column, below the photic zone. Our view can be generalized to upwelling areas where the diploid stage of $\mathrm{Coc}$ colithus pelagicus s.l. (more resistant to turbulence than the haploid stage) is found in cold and nutrientrich waters, where advection and other mixing forces are strong and result in nutrient entrainment in the water column), whereas its haploid stage is located in more oligotrophic areas (Cachão \& Moita 2000).

In conclusion, a hypothesis may be formulated whereby the natural abundance of Coccolithus braarudii and Calcidiscus leptoporus is related to their growth strategy, with their heteromorphic life cycle linked to their ecology and each morphological stage corresponding to a different ecological niche. Thus, the motile haploid stage of both species could exploit a more oligotrophic niche than the non-motile diploid stage, and, in temperate zones, we expect their distribution to be seasonal (see also the similar interpretation of Noel et al. [2004] for Calyptrosphaera sphaeroidea). This hypothesis can be integrated into the 2-dimensional phytoplankton niche space model of Margalef (1978), defined by nutrients and turbulence: the haploid (N) stage of coccolithophores would fall close to 


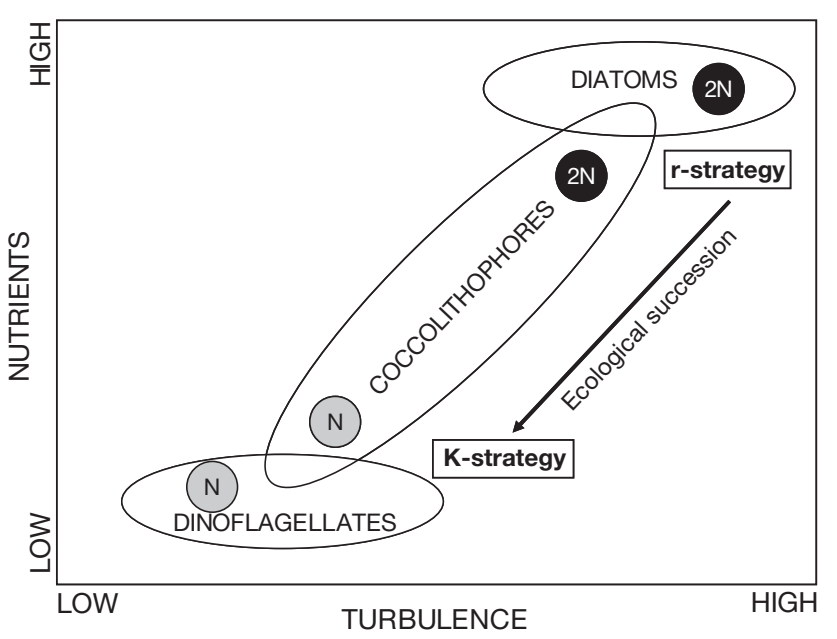

Fig. 10. Modified version of Margalef's 2-dimensional niche space model (Margalef 1978), integrating the life cycle of coccolithophores. $2 \mathrm{~N}$ : diploid stage; $\mathrm{N}$ : haploid stage

the dinoflagellates (which exploit low-nutrient and stratified regimes), whereas their diploid $(2 \mathrm{~N})$ stage could be placed next to the diatoms (which exploit high-nutrient, mixed regimes) (Fig. 10).

However, this hypothesis is probably not strictly applicable to all oceanic coccolithophores with heterococcolithophore-holococcolithophore life cycles. For example, Coronosphaera mediterranea (see Houdan et al. 2004) and other coccolithophore species, in which both haploid and diploid stages are motile, almost certainly present different growth strategies and phase distributions. Field observations with specific sampling surveys are therefore needed in order to test the above hypothesis.

Acknowledgements. This work was conducted with the financial support of the Conseil Régional de Basse-Normandie, the Agence de l'Eau Seine-Normandie and the EC-funded CODENET (Coccolithophore Evolutionary Biodiversity and Ecology) network. We thank L. Le Gall, J. R. Young, M. Geisen, M. Cachão and the CODENET team for information and fruitful discussions.

\section{LITERATURE CITED}

Beaufort L, Heussner S (2001) Seasonal dynamics of calcareous nanoplankton on a West European continental margin: the Bay of Biscay. Mar Micropaleontol 43(1-2):27-55

Berges JA, Franklin DJ, Harrison PJ (2001) Evolution of an artificial seawater medium: improvements in enriched seawater, artificial water over the last two decades. J Phycol 37:1138-1145

Billard C (1994) Life cycles. In: Green JC, Leadbeater BSC (eds) The haptophyte algae. Systematics Association Spec Vol 51, Clarendon Press, Oxford, p 167-186
Billard C, Inouye I (2004) What is new in coccolithophore biology? In: Thierstein HR, Young JR (eds) Coccolithophores-from molecular processes to global impact. Springer-Verlag, Heidelberg, p 1-29

Brand LE, Guillard RRL (1981) A method for the rapid and precise determination of acclimated phytoplankton reproduction rates. J Plankton Res 3:193-201

Cachão M, Moita MT (2000) Coccolithus pelagicus, a productivity proxy related to moderate fronts off western Iberia. Mar Micropaleontol 39:131-155

Cosson J (1987) Croissance des sporophytes issus d'hybridations interspécifiques et intergénériques chez les laminaires. Cryptogam Algol 8(1):61-72

Cros L (2002) Planktonic coccolithophores of the NW Mediterranean. $\mathrm{PhD}$ thesis, Universitat de Barcelona

Edvardsen B, Eikrem W, Green JC, Andersen RA, Moon-Van der Staay SY, Medlin LK (2000) Phylogenetic reconstructions of the Haptophyta inferred from 18S ribosomal DNA sequences and available morphological data. Phycologia 39(1):19-35

Falkowski P, Schofield O, Katz ME, Van de Schootbrugge B, Knoll AH (2004) Why is the land green and the ocean red? In: Thierstein HR, Young JR (eds) Coccolithophoresfrom molecular processes to global impact. SpringerVerlag, Heidelberg, p 429-454

Geisen M, Billard C, Broerse ATC, Cros L, Probert I, Young JR (2002) Life cycle associations involving pairs of holococcolithophorid species: intraspecific variation or cryptic speciation? Eur J Phycol 37:531-550

Houdan A, Billard C, Marie D, Not F, Sáez AG, Young JR, Probert I (2004) Holococcolithophore-heterococcolithophore (Haptophyta) life cycles: flow cytometric analysis of relative ploidy levels. Syst Biodivers 1:453-465

Jones HLJ, Leadbeater BSC, Green JC (1994) Mixotrophy in haptophytes. In: Green JC, Leadbeater BSC (eds) The haptophyte algae. Systematics Association Spec Vol 51, Clarendon Press, Oxford, p 247-264

Jordan RW, Cros L, Young JR (2004) A revised classification scheme for living haptophytes. Micropaleontology 50 (Suppl 1):55-79

Kawachi M, Inouye I, Maeda O, Chihara M (1991) The haptonema as a food-capturing device; observations on Chrysochromulina hirta (Prymnesiophyceae). Phycologia 30: 563-573

Keller MD, Selvin RC, Claus W, Guillard RRL (1987) Media for the culture of oceanic ultraphytoplankton. J Phycol 23: $633-638$

Klaveness D (1973) The microanatomy of Calyptrosphaera sphaeroidea, with some supplementary observations on the motile stage of Coccolithus pelagicus. Norw J Bot 20: 151-162

Kleijne A (1993) Morphology, taxonomy and distribution of extant coccolithophorids (calcareous nanoplankton). PhD thesis, Free University of Amsterdam

Lewis WMJ (1985) Nutrient scarcity as an evolution cause of haploidy. Am Nat 125:692-701

Liu CP, Lin LP (2001) Ultrastructural study and lipid formation of Isochrysis sp. CCMP1324. Bot Bull Acad Sin 42:207-214

López-Dóriga MV, Barnes AC, dos Santos NMS, Ellis AE (2000) Invasion of fish epithelial cells by Photobacterium damselae subsp. piscicida: evidence for receptor specificity, and effect of capsule and serum. Microbiology 146:21-30

Malin G, Steinke M (2004) Dimethyl sulphide production: What is the contribution of coccolithophores? In: Thierstein HR, Young JR (eds) Coccolithophores-from molecular processes to global impact. Springer-Verlag, Heidelberg, p 127-164 
Malone TC (1980) Algal size. In: Morris I (ed) The physiological ecology of phytoplankton. Blackwell Scientific, Oxford, p 433-463

Margalef R (1978) Life-forms of phytoplankton as survival alternatives in an unstable environment. Oceanol Acta 1: 493-509

Noel MH, Kawachi M, Inouye I (2004) Induced dimorphic life cycle of a coccolithophorid, Calyptrosphaera sphaeroidea (Prymnesiophyceae, Haptophyta). J Phycol 40:112-129

Okada H, McIntyre A (1979) Modern coccolithophores of the Pacific and North Atlantic Ocean. Micropaleontology 23(1):1-55

Paasche E (2001) A review of the coccolithophorid Emiliania huxleyi (Prymnesiophyceae), with particular reference to growth, coccolith formation, and calcification-photosynthesis interactions. Phycologia 40:503-529

Parente A, Cachao M, Baumann KH, de Abreu L, Ferreira J (2004) Morphometry of Coccolithus s.l. (Coccolithophore, Haptophyta) from offshore Portugal, during the last 200 kyr. Micropaleontology 50(Suppl 1):107-120

Parke M, Adams I (1960) The motile (Crystallolithus hyalinus Gaarder et Markali) and the non-motile phases in the life history of Coccolithus pelagicus (Wallich) Schiller. J Mar Biol Assoc UK 39:263-274

Price LL, Yin K, Harrison PJ (1998) Influence of continuous light and L:D cycles on the growth and chemical composition of Prymnesiophyceae including coccolithophores. J Exp Mar Biol Ecol 223:223-234

Probert I, Houdan A (2004) The laboratory culture of coccolithophores. In: Thierstein HR, Young JR (eds) Coccolithophores - from molecular processes to global impact. Springer-Verlag, Heidelberg, p 217-249

Renaud S, Klaas C (2001) Seasonal variations in the morphology of the coccolithophore Calcidiscus leptoporus off

Editorial responsibility: Paul Harrison,

Kowloon, Hong Kong SAR
Bermuda (N. Atlantic). J Plankton Res 23(8):779-795

Renaud S, Ziveri P, Broerse ATC (2002) Geographical and seasonal differences in morphology and dynamics of the coccolithophore Calcidiscus leptoporus. Mar Micropaleontol 46:363-385

Richerd S, Destombe C, Cuguen J, Valéro M (1993) Variation of reproductive success in a haplo-diploid red alga, Gracilaria verrucosa: effects of parental identities and crossing distance. Am J Bot 80:1379-1391

Sáez AG, Probert I, Geisen M, Quinn P, Young JR, Medlin LK (2003) Pseudo-cryptic speciation in coccolithophores. Proc Natl Acad Sci USA 100:7163-7168

Sáez AG, Probert I, Young JR, Edvardsen B, Eikrem WE, Medlin LK (2004) A review of the phylogeny of the Haptophyta. In: Thierstein HR, Young JR (eds) Coccolithophores - from molecular processes to global impact. Springer-Verlag, Heidelberg, p 251-269

Tarran GA, Zubkov MV, Sleigh MA, Burkill PH, Yallop M (2001) Microbial community structure and standing stocks in the NE Atlantic in June and July of 1996. Deep-Sea Res II 48(4-5):963-985

Tillmann U (1998) Phagotrophy by a plastidic haptophyte, Prymnesium patelliferum. Aquat Microb Ecol 14:155-160

Valéro M, Richerd S, Perrot V, Descombes C (1992) Evolution of alternation of haploid and diploid phases in life cycles. Trends Ecol Evol 7(1):25-29

Young JR (1994) Functions of coccoliths. In: Winter A, Siesser G (eds) Coccolithophores. Cambridge University Press, p 63-82

Young JR, Geisen M, Cros L, Kleijne A, Sprengel C, Probert I, Østergaard JB (2003) A guide to extant coccolithophore taxonomy. J Nanoplankton Res Spec Iss 1: 1-125 (see www.nhm.ac.uk/hosted_sites/ina/announce/ coccoguide.htm)

Submitted: May 18, 2005; Accepted: April 26, 2006

Proofs received from author(s): September 25, 2006 